\title{
NATIONAL ACADEMY OF SCIENCES-NATIONAL RESEARCH COUNCIL
}

\author{
( OMMISSION ON PHYSICAL SCIENCES, MATHEMATICS, AND APPLICATIONS \\ Board on Physics and Astronomy \\ Committee on Atomic, Molecular, and Optical Science
}
TECHNICAL PROGRESS REPORT \& CONTINUATION PROPOSAL
to the
Department of Energy
on the

\section{Committee on Atomic, Molecular, and Optical Sciences (CAMOS)}

DOE/ER/13326--5

Grant No. \#DE-FG05-85ER13326

DE93 007301

This progress report covers activities of the Committee on Atomic, Molecular, and Optical Sciences (CAMOS) for the period February 1, 1992 to January 31, 1993.

\section{SUMMARY}

The Committee on Atomic, Molecular and Optical Sciences (CAMOS) of the National Research Council (NRC) is charged with monitoring the health of the field of atomic, molecular, and optical (AMO) science in the United States. Accordingly, the Committee identifies and examines both broad and specific issues affecting the field. Regular meetings, teleconferences, briefings from agencies and the scientific community, the formation of study panels to prepare reports, and special symposia are among the mechanisms used by the CAMOS to meet its charge. This progress report presents a review of CAMOS activities from February 1, 1992 to January 31, 1993. The details of prior activities are discussed in earlier progress reports. This report also includes the status of activities associated with the CAMOS study on the field that is being conducted by the Panel on the Future of Atomic, Molecular, and Optical Sciences (FAMOS).

During the above period, CAMOS has continued to track and participate in, when requested, discussions on the health of the field. Much of the perspective of CAMOS has been presented in the recently-published report Research Briefing on Selected Opportunities in Atomic, Molecular, and Optical Sciences. That report has served as the basis for briefings to representatives of the federal government as well as the community-at-large. In keeping with its charge to monitor the health of the field, CAMOS launched a study designed io highlight future directions of the field.

\section{THE COMMITTEE}

The Committee on Atomic, Molecular, and Optical Sciences is a standing committee under the auspices of the Board on Physics and Astrinomy (BPA), Commission on P'sysical Sciences, Mathematics, and Applications (CPSMA) of the National Academy of Sciences (NAS)--National Research Council. CAMOS is a multidisciplinary committee with membership drawn from universities, industry, government, and national laboratories. Areas of expertise on the committee include atomic physics, molecular science, and optical science. A special effort has been made to include a balanced represeniation from the three subfields. [See attached roster.]

The atomic molecular, and optical sciences represent a broad and diverse field in which much of the research is carried out by small groups. These groups generally have not operated in concert with each other and, prior to the establishment of IAMOS, there was no single committee or organization that accepted the responsibility of monitoring the conti uuing development and assessing the general health of the field as a whole. CAMOS has accepted this responsibility and currently provides a focus for the AMO community that is unique and essential. 
The operating guidelines of the Committee, originally created in 1970, include the following: (1) to provide a source from which the federal agencies could cbtain technical advice and assistance; (2) to initiate and oversee the conduct and publication of studies concerning atomic, molecular, and optical science and its multidisciplinary connections to other fields of science and technology; (3) to provide a forum for discussion among atomic, molecular, and optical scientists and, thereby, provide a unifying force in this diverse and varied field; and (4) to provide an interface for communication among the atomic, molecular, and optical science communities and federal agency program directors who fund research in the field. These objectives continue to serve as the guidelines for the committee and, in response, several mechanisms have been developed to achieve these objectives. In particular, CAMOS organizes and conducts special technical studies, surveys, workshops, and other meetings. CAMOS also functions as an oversight committee for ad hoc panels charged with the task of preparing reports on specific issues or topics. Symposia held at the National Academy of Sciences or at research centers have been used to focus attention on particular issues connected with facilities, programs, or other matters of concern to the AMO community. CAMOS continues to use these mechanisms to develop and undertake new projects.

CAMOS has conducted a number of studies related to the health of atomic and molecular science and is well prepared to respond to requests for studies on a broad array of topics and issues. Specific report-generating projects under the aegis of the CAMOS are separately proposed and funded as the committee identifies key issues itself or accepts requests from agencies of the government and develops corresponding activities.

\section{Highlights of Recent Meetings of the Committee}

Regular meetings of the Committee and special meetings with federal agency representatives and the scientific community are essential to maintaining continuous contact with both groups. The highlights of meetings held during the period February 1, 1992 to January 31, 1993 are presented below:

December 6, 1991(Washington, DC). [Although this moeting occurred before the current performance period began, it impacted the Committee's activities during the performance period.] The primary business items on the agenda were the following: (1) a review of highlights of the October 28, 1991 meeting of the Panel on the Future of Atomic, Molecular, and Optical Sciences (FAMOS), (2) a discussion on the supporting role of CAMOS to that activity, and (3) an evaluation of the results of a survey of AMO experimental physicists. A portion of the agenda was devoted to informal discussions with agency representatives from DOE, NSF, and NIST. [Minutes available upon request.]

May 20, 1992 (Chicago, IL). This was a joint meeting involving representatives of both CAMOS and FAMOS. Several action items were discussed, including a proposed study on optical sciences and engineering (to follow the FAMOS study), the FAMOS study and the involvement of the AMO community in generating the report, a Town meeting that would be held that evening, and the May 12,1992 presentation by Gordon Dunn, CAMOS Chair, to the NSF Advisory Committee for Physics (ACP). The representatives discussed how to respond to an NSF request for the AMO community to provide the $\mathrm{ACP}$ with information on the connections between AMO science and the FCCSET initiatives. [Minutes available upon request.]

September 14, 1992 (Washington, DC). The fall 1992 meeting of CAMOS focused on several areas. The progress of the FAMOS study was reviewed. There was an extended discussion on BPA plans to hold a program initiation meeting on optical science and engineering following completion of the FAMOS report. A CAMOS member presented a proposal for the formation of a National Transfer Agency. A representative from NSF presented the agency's response to the proposal. Finally, there was a lengthy discussion involving Committee members and agency representatives from DOE, NSF, NIST, AFOSR, ONR, and NASA on the connection between AMO science and the FCCSET initiatives. [Minutes available upon request.]

\section{CAMOS Briefings and Representation at Other Meetings}

Committee members are often requested to brief agency representatives, the scientific community, or other groups on matters of importance to the AMO community-at-large. The highlights of these activities during the period February 1, 1992 to January 31, 1993 are presented below: 
May 11-12, 1992 (Washington, DC). The CAMOS Chair attended the May 1992 meeting of the National Science Foundation (NSF) Advisory Committee on Physics (ACP). Drawing on the CAMOS report Research Briefing on Selected Opportunities in Atomic, Molecular, and Optical Sciences, the Chair reviewed the activities of CAMOS as well as FAMOS.

June 29, 1992 (Washington, DC). The CAMOS Vice Chair (and the FAMOS Chair) attended the annual Interagency Meeting of the Atomic, Molecular, and Optical Physics Program Managers. Both CAMOS and FAMOS activities were reviewed. The program managers were called on to assist the FAMOS Panel by providing detailed data on federal support for AMO science.

\section{STATUS OF CAMOS PROJECTS}

\section{Summary}

Over the past several years, CAMOS initiated or completed several projects. Under the auspices of CAMOS, the Panel on the Future of Atomic, Molecular, and Optical Sciences began an assessment of the scientific and technological developments and opportunities in the field. The study will both assess the state of knowledge in AMO science and also lay out priorities of the community in pursuing its research agenda over the next several years. In response to a request from the Director of the Office of Energy Research of the Department of Energy, CAMOS prepared a brief report presenting the Committee's perspective on the field-Research Briefing on Selected Opportunities in Atomic, Molecular, and Optical Sciences (National Academy Press, Washington, DC, 1991). The purpose of this rapidly-prepared report was to facilitate the implementation of the broader assessment of AMO science mentioned above and to provide preliminary information that would be of use to the agencies for FY93 program planning. [A copy of the briefing-Research Briefing on Selected Opportunities in Atomic, Molecular, and Optical Sciences-is available upon request.]

In addition, CAMOS has undertaken several other projects, including the following:

- Survey of AMO Experimentalists

- Optical Sciences and Engineering Study

- Workshop on Database Needs for Plasma Processing of Materials

The current status of these projects bears directly on the activities of CAMOS during the performance period for this contract.

\section{Survey of AMO Experimentalists}

In response to concerns over the current status and health of the experimental segment of AMO physics, CAMOS developed and distributed a questionnaire to that specific segment of the research community. The data was tabulated and reviewed at the December 1991 meeting. It was decided to turn this information over to the FAMOS Panel for further analysis and use in that report, if desired.

\section{Program Initiation of a Study on Optical Sciences and Engineering}

CAMOS representatives have worked together with members of FAMOS and the BPA to develop plans to hold a program initiation meeting to determine the desirability and need of a broad study on optical sciences and engineering. Such a study would follow completion of the FAMOS report. A detailed description is given in the attached prospectus. 


\section{Workshop on Database Needs for Plasma Processing of Materials}

Currently, CAMOS is discussing whether to sponsor, jointly with the Plasma Science Committee (PLSC) of the NRC, a workshop on database needs for plasma processing of materials. The need for improved database was identified in the recent NRC report Plasma Processing of Materials: Scientific opportunities and Technological Challenges. The workshop would be to bring a small group of experts together so that they may develop a specific, prioritized list of needs, appropriate action items, and an assessment of the potential impact on technology. Workshop participants would be expected to create a matrix that relates processes to the most important data base and diagnostic needs. Topics would include the following: electron and ion impact ionization, dissociation, and excitation cross sections; ion transport cross sections, particularly in the energy range from $1 \mathrm{eV}$ to $100 \mathrm{eV}$; ion molecule reaction cross sections for ion energies in the same energy range; database generation and dissemination; theoretical capability; experimental capability; surface reaction probabilities and surface kinetics for free radicals, ions, and electrons; state-of-the-art plasma process simulation and plasma reactor design; and state-of-the-art plasma diagnostic capabilities.

\section{The Future of Atomic, Molecular, and Optical Sciences}

Following the preparation of the report Research Briefing on Selected Opportunities in Atomic, Molecular, and Optical Sciences, CAMOS proposed that a detailed study on the scientific and technological opportunities of the field be conducted to assess the state of knowledge of the field of atomic, molecular, and optical science and to identify the priorities of the community in pursuing its research agenda over the next several years. The project received sufficient funding (from DOE, NSF, AFOSR, and NASA) and is now underway.

The Panel on the Future of Atomic, Molecular, and Optical Sciences (see attached roster) is chaired by Dr. Neal Lane (Rice University) with Dr. Gordon Dunn (JLA) serving as Executive Co-Chair. The Panel held its inaugural meeting on October 28, 1991 and developed an action plan to address the formal charge to the Panel, which includes the following:

- Determines manpower, instrumentation, facility, and funding requirements not only in the context of the intellectual challenges of AMO science, but also in the context of national needs such as (a) science education; (b) defense, energy, space, and environmental applications; (c) industrial and technological competitiveness; and (d) appropriate aspects of human health and welfare.

- Seeks to identify scientific forefronts, technological opportunities, and windows of future opportunity.

- Seeks to establish sets of research and educational priorities from various perspectives.

- Sets forth goals and planning scenarios that reflect these research and educational priorities.

- Develops long-range strategies that will best meet the goals set forth.

- Assesses the institutional infrastructure in which AMO science is conducted and identifies changes that would improve its constituent research and educational efforts.

- Provides a comparison of AMO science in the United States with its counterpart in other industrialized nations.

- Reviews the scientific advances made during the last decade.

In addressing the charge, FAMOS has solicited input from many segments of the community. For example, letters were sent to key AMO scientists and professional organizations. The Panel wrote to over 300 AMO scientists requesting comments and input that could be used to address the charge. The responses generally endorsed the efforts of the Panel as well as pointed to a field of excitement and opportunity. Also, letters were written to the officers of the American Physical Society's (APS) Division of Atomic, Molecular, and Optical Physics (DAMOP), Division of Chemical Physical (DCP), Laser Science Topical Group (LSTG); IEEE Lasers and Electro-Optics Society; Optical Society of American (OSA); and others requesting advice on matters that warranted attention by the Panel, requesting help with publicity through society newsletters and at meetings, and requesting input on any of the issues outlined in the charge. To reach members of the AMO community-at-large, the Panel developed and conducted an extensive survey. The survey was designed in consultation with survey experts at the NRC Office of Scientific and Engineering Personnel (OSEP). Over 20,000 questionnaires were mailed to atomic, molecular, and optical (AMO) PhD scientists throughout the United States. The AMO scientists 
were identified from the membership lists of several professional societies, including, the American Physical Society, the American Chemical Society, the Materials Research Society, the Optical Society of America, IEEE/Lasers and Electro-optics Society, and SPIE. Tabulation and analysis of the results has required a large amount of effort from the Panel.

To conduct the study, FAMOS has met several times and interacted with different groups. A summary is presented below:

January 22, 1992 (Teleconference by the Molecular Sciences Subpanel). The subpanel decided to partition the molecular sciences into 5 categories-molecules on surfaces; fast dynamics and coherent processes; small molecules, dynamics, and high resolution spectroscopy; clusters; and molecular theory. In addition to the APS Division of Atomic, Molecular, and Optical Physics (DAMOP), the APS Division of Chemical Physics (DCP) and the American Chemical Society (ACS) Division of Physical Chemistry (DPC) would be targeted for cooperation.

January 23, 1992 (Teleconference by the Atomic Physics Subpanel). The subpanel decided to partition the area of atomic physics into 5 categories-elementary atomic physics; atomic structure; atomic dynamics; special techniques; and interface areas. DAMOP would be the primary target of this group; a town meeting was scheduled for the May 1992 DAMOP meeting.

January 24, 1992 (Meeting of the Optical Sciences Subpanel in New York City). The subpanel decided to partition the area of optical sciences into 7 categories-laser spectroscopy; nonlinear optics; quantum optics; optical interactions with condensed matter; ultrafast optics; physics of coherent light sources; and supporting science and technology. The APS Laser Science Topical Group (LSTG) and the Optical Society of America (OSA) would be the primary target of this group. A town meeting was scheduled for the joint Quantum Electronic and Laser Science Conference (QELS)-Conference on Lasers and Electro-Optics (CLEO) meeting in May.

April 25 - 26, 1992 (Washington, DC). Neal Lane, FAMOS Chair, gave a presentation to the BPA at its spring meeting. The status of the panel's activities was reviewed and the BPA provided feedback and advice on the plan of action.

May 12,1992 (Anaheim, CA). The Optical Sciences Subpanel conducted a Town Meeting at the CLEO/QELS'92 meeting. The optical community was briefed on the status and charge to the Panel and invited to comment and to provide input.

May 12, 1992 (Washington, DC). The Executive Co-Chair briefed the NSF ACP. (See earlier discussion above).

May 20, 1992 (Chicago, IL). FAMOS representatives held a Town meeting at the Annual DAMOP meeting. The APS AMO physics community was briefed on the status and charge to the Panel and invited to comment and to provide input.

June 29, 1992 (Washington, DC). The FAMOS Chair briefed the AMO Program Managers on the status of the study and requested assistance. (See earlier discussion above.)

July 14, 1992 (Teleconference by FAMOS subpanel Chairs). The Chair and Executive Co-Chair reviewed the status of the subpanel activities and set a schedule for producing drafts of the report.

August 10-11, 1992 (Washington, DC). FAMOS met to review the drafts of the section outlines for the report, discuss action plans, and set assignments.

October 4-6, 1992 (Washington, DC). At this 3-day retreat, the Panel discussed the issues that would be addressed in the report, came to an agreement on the first cut of priorities, and wrote sections of the report to be further developed following the meeting.

As oversight committee for the panel, CAMOS continues to assist the Panel in addressing the charge. Following completion of the study, CAMOS will actively promote and disseminate the results of the study. 


\title{
Attachments
}

(1) Roster of the Committee on Atomic, Molecular, and Optical Sciences (CAMOS)

(2) Prospectus for a Program Initiation Meeting to Consider an Assessment of Optical Sciences and Engineering

(3) Roster of the Panel on Future Opportunities in Atomic, Molecular, and Optical Sciences (FAMOS)

\section{DISCLAIMER}

\begin{abstract}
This report was prepared as an account of wcrk sponsored by an agency of the United States Government. Neither the United States Government nor any agency thereof, nor any of their employees, makes any warranty, express or implied, or assumes any legal liability or responsibility for the accuracy, completeness, or usefulness of any information, apparatus, product, or process disclosed, or represents that its use would not infringe privately owned rights. Reference herein to any specific commercial product, process, or service by trade name, trademark, manufacturer, or otherwise does not necessarily constitute or imply its endorsement, recommendation, or favoring by the United States Government or any agency thereof. The views and opinions of authors expressed herein do not necessarily state or reflect those of the United States Government or any agency thereof.
\end{abstract}




\section{NATIONAL RESEARCH COUNCIL}

\section{COMMISSION ON PHYSICAL SC,ENCES, MATHEMATICS, AND APPLICATIONS}

2101 Constitution Avenue Washington, D.C. 20418

BOARD ON

PHYSICS AND ASTRONOMY

(202) 334-3520

FAX: (202) 334-2791

EMAIL: BPA@NAS.EDU

\section{COMMITTEE ON ATOMIC, MOLECULAR, AND OPTICAL SCIENCES}

Terms expire on June 30 of year indicated.

Daniel J. Larson (Chair) 1995

Department of Physics

McCormick Road

University of Virginia

Charlottesville, VA 22901

(804) $924-6782,6794$

Fax: (804) 924-4576

Email: djl@virginia.bitnet

Howard C. Bryant 1994

Department of Physics and Astronomy

University of New Mexico

Albuquerque, NM 87131

(505) 277-3044

Fax: (505) 277-1520

Email: hzero@unmb.bitnet

Sylvia T. Ceyer 1994

Department of Chemistry

Massachusetts Institute of Technology

Room 6-225

Cambridge, MA 02139

(617) 253-4537

Fax: (617) 253-7030

Email: stceyer@athena.mit.edu

Steven Chu 1995

Physics Department

Stanford University

Stanford, CA 94305

(415) 723-3571

Fax: (415) 723-9173

Gordon H. Dunn (Past Chair) 1993

Joint Institute Laboratory for Astrophysics

Campus Box 440

University of Colorado

Boulder, CO 80309-0440

(303)492-7824

Fax: (303) 492-5235

Email: gdunn@jila
Daniel Grischkowsky 1993

Department of Physical Science

IBM T.J. Watson Research Center

P.O. Box 218

Yorktown Heights, NY 10598

(914) 945-2057, 1493

Fax: (914) 945-2141

Andrew U. Hazi 1993

Lawrence Livermore Laboratory, L-296

University of California

P.O. Box 808

Livermore, CA 94550

(510) $422-4574$

Fax: (510) $294-4320$

NAS William Klemperer 1993

Chemistry Department

Harvard University

Cambridge, MA 02138

(617) 495-4094

Fax: (617) 495-1792

Email: klemperer@huchel

NAS Donald H. Levy 1993

James Franck Institute

University of Chicago

5640 South Ellis Avenue

Chicago, Il 60637

(312) 702-7196

Fax: (312) 702-5863

Email: levy@silly.uchicago.edu

Ronald E. Olson 1994

Curators' Professor of Physics

Department of Physics

University of Missouri

Rolla, MO 65401

(314) $341-4933$

Fax: (314) 341-4715

Email: c2854@umrvmb.bitnet 


\section{COMMITTEE ON ATOMIC, MOLECULAR, AND OPTICAL SCIENCES}

All terms end June 30 of year indicated.

Ronald Phaneuf 1993

Department of Physics $/ 220$

University of Nevada-Reno

Reno, NV 89557-0058

(702) $784-6818,6792$

Fax: (702) 784-1398

Email: phaneuf@envoy.physics.unr.edu

Yuen-Ron Shen 1994

Department of Physics

University of California

Berkeley, CA 94720

(510) $642-4856$

Fax: (510) 643-8923

Email: shenyr@physics.berkeley.edu

Richard E. Slusher 1994

AT\&T Bell Laboratories

Room 1D-227

600 Mountain Avenue

Murray Hill, NJ 07974

(908) 582-4094

Fax: (908) 582-4702

Email: res@physics.att.com

William Stwalley 1995

Center for Laser Science and Technology

University of lowa

Iowa City, IA 52242

(319) 335-1299

Fax: (319) 335-2951

Email: blawcspd@viamvs

NRC Committee Liaisons

Bernd Crasemann

(Chair, NIST Panel on Physics)

Department of Physics

University of Oregon

Eugene, OR 97403

(503) $346-4754$

FAX: (503) 346-4791

Professional Society Liaison Representatives

Richard Freeman

(Chair, APS, LSTG)

Room 1E-338

AT\&T Bell Laboratories

600 Mountain Avenue

Murray Hill, NJ 07974

(908) $582-4558$

Fax: (908) 582-2121

\author{
Reginald Hill \\ (Chair, OSA, DOS) \\ ERL/Wave Propagation Laboratory \\ Mail Code R/E/WPI \\ 325 Broadway \\ Boulder, CO 80303 \\ William Kupke \\ (Chair, OSA, DQE) \\ Lawrence Livermore National Laboratory \\ MS L-488 \\ P.O. Box 5508 \\ Livermore, CA 94550 \\ Tingye $\mathrm{Li}$ \\ (Chair, OSA, DP) \\ AT\&T Bell Laboratories \\ Crawford Hill Laboratory \\ Room HOH R 117 \\ P.O. Box 400 \\ Holmdel, NJ 07733 \\ Alexander Pines \\ (Chair, APS, DCP) \\ Department of Chemistry \\ University of California \\ Berkeley, CA 94720 \\ David J. Wineland \\ (Chair, APS, DAMOP) \\ National Institute of Standards and Technology \\ Division 576-11 \\ 325 Broadway \\ Boulder, CO 80303 \\ (303) 497-5286 \\ Fax: (303) 497-64C1 \\ NRC Staff \\ Donald C. Shapero, Director \\ Email: dshapero@nas \\ Ronald D. Taylor, Senior Program Officer \\ Email: rtaylor1@nas \\ Board on Physics and Astronomy \\ National Research Council \\ 2101 Constitution Avenue \\ Washington, DC 20418 \\ (202) $334-3520$ \\ Fax: (202) 334-2791 \\ Email: bpa@nas.edu
}


July 15, 1992

Prospectus

\section{COMRISSION ON PHYSICAL SCIENCES, MATHEMATICS, AND APPLICATIONS COMMISSION ON ENGINEERING AND TECHNICAL SYSTEMS}

Assessment of Optical Sciences and Engineering

Board on Physics and Astronomy, National Materials Advisory Board

SUMMARY: A program initiation meeting is proposed that would bring together experts in optical science and optical engineering, as well as users of advanced optics (for example, astronomers knowledģeable in advanced optical techniques such as ion-beam mirror figuring) to evaluate the status of these areas and whether a multidisciplinary assessment would be useful at present. If the group concludes that such an assessment would be useful, they would be asked to prepare a planning document for the BPA defining the scope, objectives, and audience of the activity.

BACKGROUND: Under the Board on Physics and Astronomy's Committee on Atomic, Molecular, and Optical Sciences (CAMOS), the Panel on the Future of Atomic, Molecular, and Optical Sciences (FAMOS) is preparing an assessment of that field. From the outset, Panel discussions with members of the AMO community, and in particular, the optical scientists, have pointed to the difficulty in constructing the proper operational definition of optical science. As a result of these discussions and its deliterations, the FAMOS Panel has chosen to restrict its study to those topics that are typically covered in the International Quantum Electronics Conference (IQEC) or the Quantum Electronics and Laser Science Conference (QELS). These topics include laser spectroscopy, nonlinear optical phenomenon, quantum optics, optical interactions with condensed matter, ultrafast optics, and coherent light sources. Although this definition is broader than in past NRC studies (e.g., Physics Through The 1990s: Atomic, Molecular, and Optical Physics), many interesting and exciting developments in optical science and engineering fall outside the scope of the FAMOS assessment.

There have been several discussions within the FAMOS Optical Sciences Subpanel about the possibility of a broader and more comprehensive study of optical sciences and engineering. Recently, the Optical Sciences Subpanel discussed this issue with the Technical Council of the Optical Society of America (OSA). The need for a broader assessment has been acknowledged. It is also recognized that such an assessment must address the full breadth of science and engineering developments that concern the many optical societies-OSA, IEEE/Lasers and Electro-Optics Society, APS/Laser Science Topical Group, for example.

This issue was also discussed at the April 1992 meeting of the Board on Physics and Astronomy and at the May meeting of the Commission on Physical Sciences, Mathematics, and Applications. The CPSMA has asked the BPA to explore the possibility of a study of Optical Sciences and Engineering (OS\&E). The BPA has had preliminary consultations with the Commission on Engineering and Technical Systems and its National Materials Advisory Board 
which confirm the importance of participation of the engineering community working in the optics area. following:

A sampling of the scientific topics that might be addressed in such a meeting includes the

\section{- Optical science}

Quantum optics (squeezed states, photon statistics, optical molasses)

Quantum electronics (cavity quantum electrodynamics; ultrafast optical phenomena)

Lasers: solid, liquid, and gas phase; free-electron lasers

Nonlinear optics

Classical optics

Extreme ultraviolet and $\mathrm{x}$-ray techniques

Surface physics

- New technologies

Binary optics (e.g., VLSI techniques for fresnel optics)

Ion-beam mirror figuring for telescopes

Adaptive optics

Interferometry (including speckle)

Lithography

$\mathrm{X}$-ray multilayers

Photonics

Laser fusion

- Relationships to other ficids

The role of materials and solid-state physics: nonlinear optical materials; use of lasers for materials processing; quantum-well lasers

The role of plasma science (for understanding gas-phase lasers, laser-plasma interactions for generating high electric fields)

The role of atomic and molecular sciences (based on results of FAMOS study)

Gravitational physics (laser-interferometric gravity-wave detectors)

Atmospheric, space, and ocean sciences.

Accelerator science (alignment, high-field-gradient devices)

- Applications

Communications and information processing

Displays and imaging

Medicine and vision

Lithography and processing

Sensor technology

Positioning: (laser ranging, optical gyros)

Electromagnetic interference effects (use of fiber-optic interconnects in high-speed electronics) 
PROPOSED PLAN OF ACTION: A panel would be convened to consider the question of the desirability of a multidisciplinary assessment of optical sciences and engineering. The panel would have expertise on the topics listed above. It would also include users of optical science and technology. The panel would discuss the scope of an assessment of this area, building on existing studies (e.g., Photonics: Maintaining Competitiveness in the Information Era) and studies in progress (the FAMOS assessment). The panel's assessment would form the basis of a document for use in planning further work in this area, should the panel so recommend.

ANTICIPATED RESULTS: The PI group would make a recommendation on whether a study of Optical Sciences and Engineering is merited at present. If the recommendation is positive, then the group would prepare a study plan addressing (1) the role of priority setting in this field,

(2) issues that connect the science to societal needs, (3) dissemination of the results of the study,

(4) the best ways to establish contact with the many involved disciplines, (5) applications,

(6) audiences for the report, (7) mechanisms for follow-up.

RESPONSIBLE STAFF OFFICERS: Donald C. Shapero, Director, and Ronald D. Taylor, Senior Program Officer, Board on Physics and Astronomy, HA-562, ext. 3520. 


\section{NATIONAL RESEARCH COUNCIL}

\section{COMMISSION ON PHYSICAL SCIENCES, MATHEMATICS, AND APPLICATIONS}

2101 Constitution Avenue Washington, D.C. 20418

BOARD ON

PHYSICS AND ASTRONOMY

(202) 334-3520

FAX: (202) 334-2791

EMAIL: BPA@NAS.EDU

\section{PANEL ON THE FUTURE OF ATOMIC, MOLECULAR, AND OPTICAL SCIENCES}

All terms end on June 30, 1994.

Neal Lane (Chair)

Provost

Rice University

P.O. Box 1892

Houston, TX 77251

(713) $527-4026$

Fax: (713) 285-5271

Email: neal@rice vml.rice.edu

Gordon H. Dunn (Executive Co-Chair)

Joint Institute Laboratory for Astrophysics

Campus Box 440

University of Colorado

Boulder, CO 80309-0440

(303) 492-7824

Fax: (303) 492-5235

Email: gdunn@jila

Lloyd Armstrong, Jr.

Office of the Dean

School of Arts and Sciences

Johns Hopkins University

Baltimore, MD 21218

(410) $516-8212$

Fax: (410) 516-6017

Email: arm@jhuvm

Louis E. Brus

AT\&T Bell Laboratories

600 Mountain Avenue

Murray Hill, NJ 07974

(908) $582-3119$

Fax: (908) 582-3958

Sylvia T. Ceyer

Department of Chemistry

Massachusetts Institute of Technology

Building 6-225

Cambridge, MA 02139

(617) 253-4537

Fax: (617) 253-7030

Email: stceyer@athena.mit.edu
F. Fleming Crim

Department of Chemistry

University of Wisconsin

1101 University Avenue

Madison, WI 53706

(608) 263-7364

Fax: (608) 262-0381

Email: fcrim@chem.wisc.edu

\author{
Alexander Dalgarno \\ Harvard-Smithsonian Center for Astrophysics \\ 60 Garden Street \\ Cambridge, MA 02138
}

(617) 495-4403

Fax: (617) 495-5970

Email: dalgarno@cfa

F. Barry Dunning

Rice University

P.O. Box 1892

Houston, TX 77251

(713) 527-8101, ext. 3544

Fax: (713) 285-5143

NAE Elsa M. Garmire

Center for Laser Studies

University of Southern California

University Park 1112

Los Angeles, CA 90089-1112

(213) $740-4238$

Fax: (213) 740-8158

\author{
Paul L. Kelley \\ Electro-Optics Technology Center \\ Tufts University \\ 4 Colby Street \\ Medford, MA 02155 \\ (617) 627-3136 \\ Fax: (617) 627-3151 \\ Email: pkelley@pearl.tufts.edu
}




\section{PA NEL ON THE FUTURE OF ATOMIC, MOLECULAR, AND OPTICAL SCIENCES}

All terms end on June 30, 1994.

Daniel J. Larson

Department of Physics

McCormick Road

University of Virginia

Charlottesville, VA 22901

(804) 924-6782, 6794

Fax: (804) 924-4576

Email: djl@virginia

\section{Paul Liao}

Assistant Vice President

Network Systems Research Laboratory

Bellcore

331 Newman Springs Road, Room $3 Z 333$

Red Bank, NJ 07701-704n

(908) $758-3100$

Fax: (908) 758-4371

Email: liao@troy.cc.bellcore.com

Stmhen R. Lundeen

I.

Demeadernent of Physics

University of Notre Dame

Notre Dame, IN 46556

(219) 239-7398

Fax: (219) 239-5952

Thomas J. Mcllrath

Institute of Physical Sciences and Technology

University of Maryland

College Park, MD 20742

(301) $405-4814$

Fax: (301) 314-9404

Email: tjm@ipst.umd.edu

Peter W. Milonni

Los Alamos National Laboratory

Mail Stop B212

Los Alamos, NM 87545

(505) $667-7763$

Fax: (505) 665-6229

Email: pwm@photon.lanl.gov

Richard C. Powell

Optical Sciences Center

University of Arizona

Tucson, AZ 85721

(602) $621-6997$

Fax: (602) 621-9613

\section{NRC Staff}

Donald C. Shapero, Director

Email: dshapero@nas

Ronald D. Taylor, Senior Program Officer

Email: rtaylor1@nas

Board on Physics and Astronomy

National Research Council

2101 Constitution Avenue

Washington, D.C. 20418

(202) $334-3520$

Fax: (202) 334-2791

Email: bpa@nas 

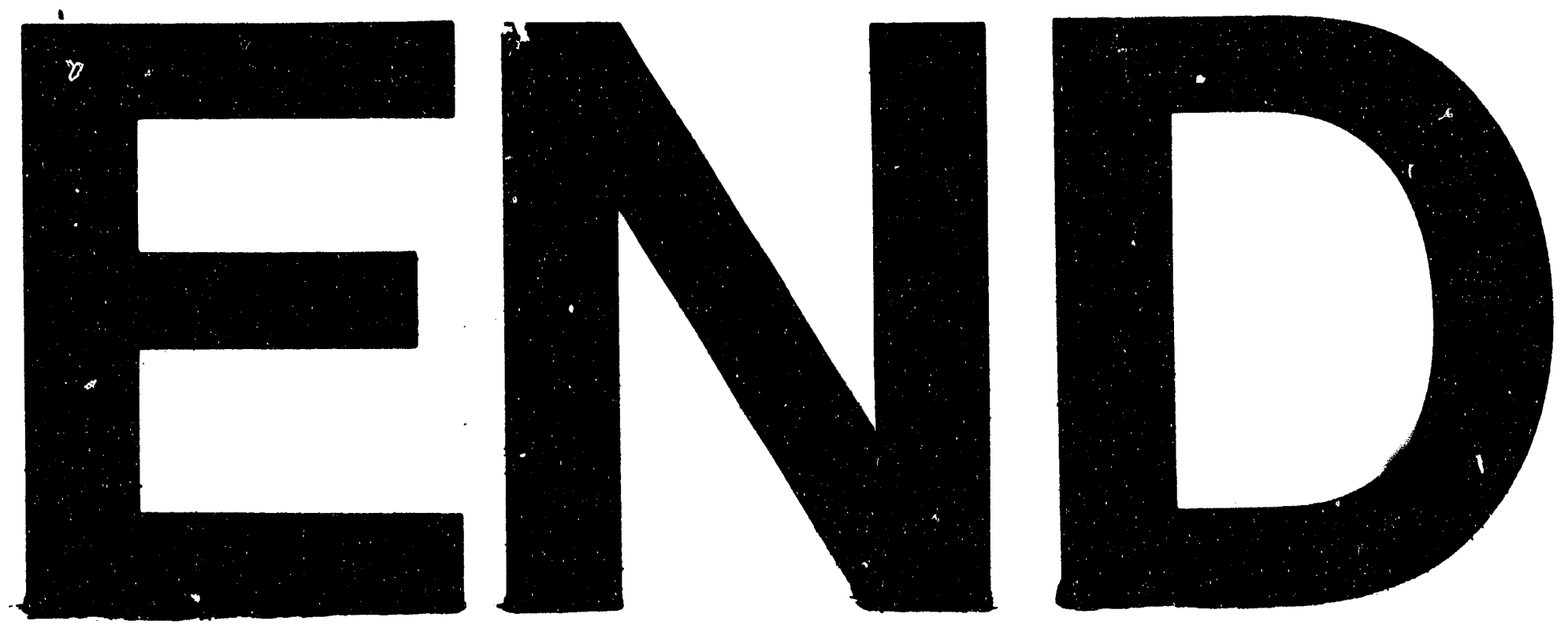

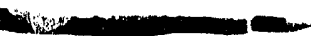

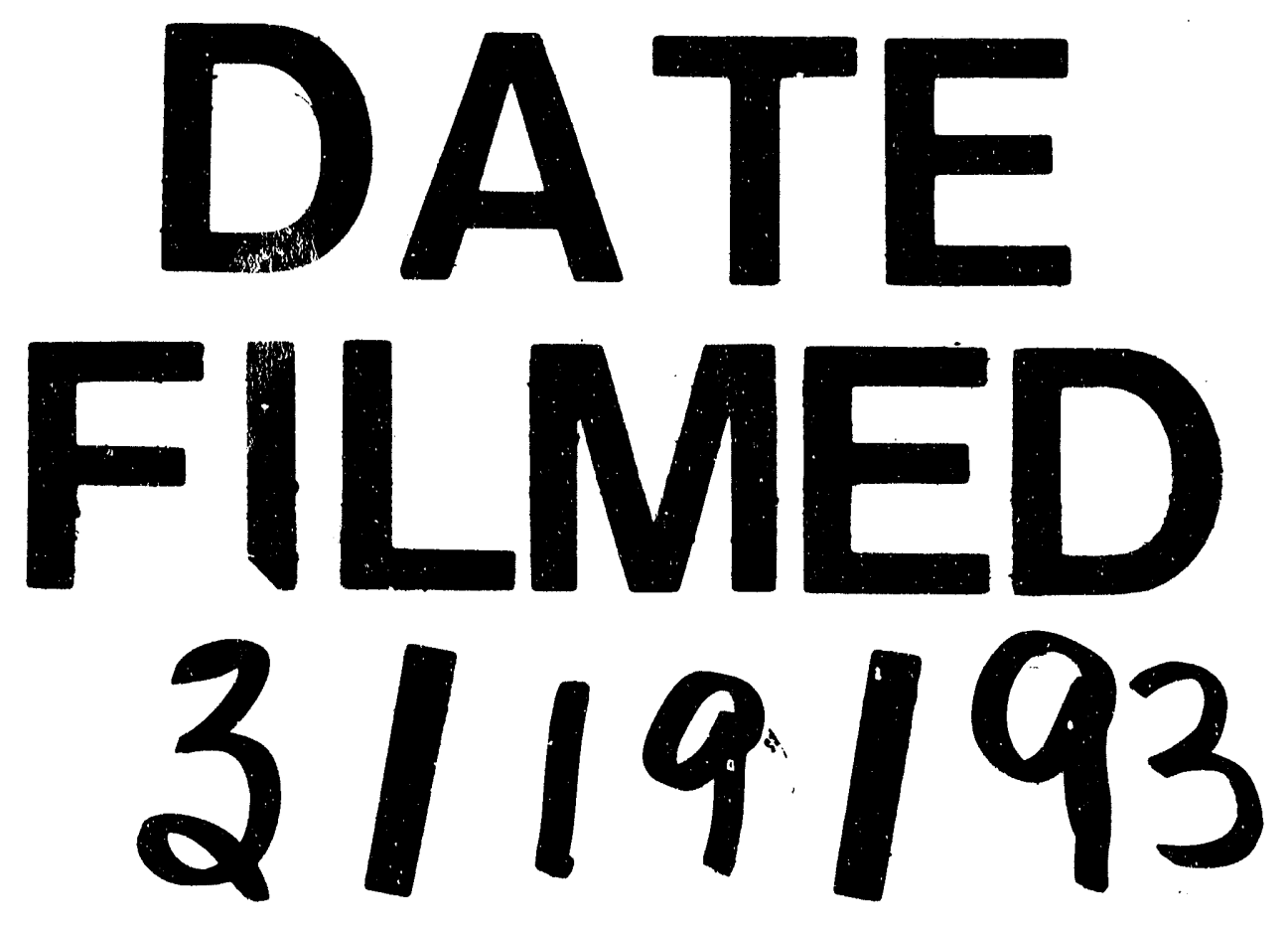


